Division of Research

November 1982

Graduate School of Business Administration

The University of Michigan

STRATEGIC IMPLICATIONS OF

MARKET SHARE ATTRACTION MODELS

Working Paper No. 318

Anee1 Karnani

The University of Michigan

FOR DISCUSSION PURPOSES ONLY

None of this material is to be quoted or reproduced without the expressed permission of the Division of Research. 


\title{
STRATEGIC IMPLICATIONS OF MARKET SHARE ATTRACTION MODELS
}

\begin{abstract}
Market share attraction models, which specify that a firm's market share is equal to the ratio of its "attraction" to the total attraction for all firms, have received increasing attention in recent years. However, there has been little research investigating the practical implications of such models. This paper presents a game-theoretic analysis of such a model and deduces the strategic implications of a Nash equilibrium solution to the model. It is shown that these implications are consistent with previous empirical research in marketing and business policy.
\end{abstract}


Market share attraction models have received increasing attention in the marketing literature in recent years. In general, a market share attraction model specifies that the market share of a firm is equal to its "attraction" divided by the total attraction of all the firms in the market, where a firm's attraction is a function of the values of its marketing instruments. Such models are theoretically appealing because they are logically consistent: that is, they yield market shares that are between zero and one, and sum to one across all the firms in the market (Naert and Bultez, 1973; Naert and Weverbergh, 1981). Nakanishi and Cooper (1974) present a theory for parameter estimation for a large class of such models. Several empirical studies have used the attraction specification to model market shares. ${ }^{1}$ on the basis of comparative empirical results for two markets (gasoline and electric razors), Naert and Weverbergh (1981) tentatively conclude that the market share attraction models have better predictive power than the more classic market share specifications (that is, linear additive and multiplicative).

Given this empirical interest in market share attraction models, it is not surprising that some theoretical research has also been done on these models. Be11, Keeney, and Little (1975) derive a general market share attraction model from a few plausible axioms. ${ }^{2}$ Kotler (1965) uses a market share attraction model in a simulation study of marketing strategies in a competitive duopoly. Simon (1978) presents an analytical investigation of Kotler's (1965) simulation model. Market share attraction models are particularly amenable to game-theoretic analysis of oligopolistic competition because they are logically consistent and explicitly take into account the competitive interaction among the firms in the market. Unfortunately, however, all the previous research which has offered a game-theoretic analysis of oligopolistic competition using the market share attraction model has assumed that the firms compete only on the advertising or promotion dimension (for example, Friedman, 1958; Mills, 
1961; Shakun, 1965 and 1966; Baligh and Richartz, 1967; Balch, 1971;

Schmalensee, 1976). In other words, it was assumed that all the firms charge the same price for their products, and control only one decision variable: advertising (or promotion) expenditure. This is, of course, not consistent with the empirical research using the market share attraction model which has explicitly taken into account the marketing mix concept.

In a critique of Bell, Keeney, and Little's (1975) axiomatic derivation of market share attraction models, Chatfield (1976, p. 310) argues that more effort must be made to "demonstrate the practical implications, if any, of the results." The objective of this paper is to deduce the practical implications of market share attraction models. In terms of the paradigm of industrial organization (for example, Scherer, 1980, Chapter 1), this paper investigates the conduct of the firms and the performance of the market, assuming that the structure of a market can be represented by a market share attraction model. More specifically, this paper presents a game-theoretic analysis of market share attraction models using the solution concept of a Nash equilibrium, and deduces the strategic implications of such an equilibrium. It is shown that these implications are consistent with previous empirical research in marketing and business policy.

Below, the model used to represent oligopolistic competition is described first. A characterization of a Nash equilibrium solution to this model is then derived. Finally, the solution is interpreted.so as to deduce the practical implications of the model, and it is argued that these implications are consistent with previous empirical research.

\section{The Mode1}

The model discussed in this paper is a static, one-period model. It would clearly be more realistic and more interesting to analyze a dynamic model; 
however, for the sake of analytical tractability we assume a static model, and suggest the extension to the dynamic case as an avenue for further research.

The symbols used in the model are defined as follows:

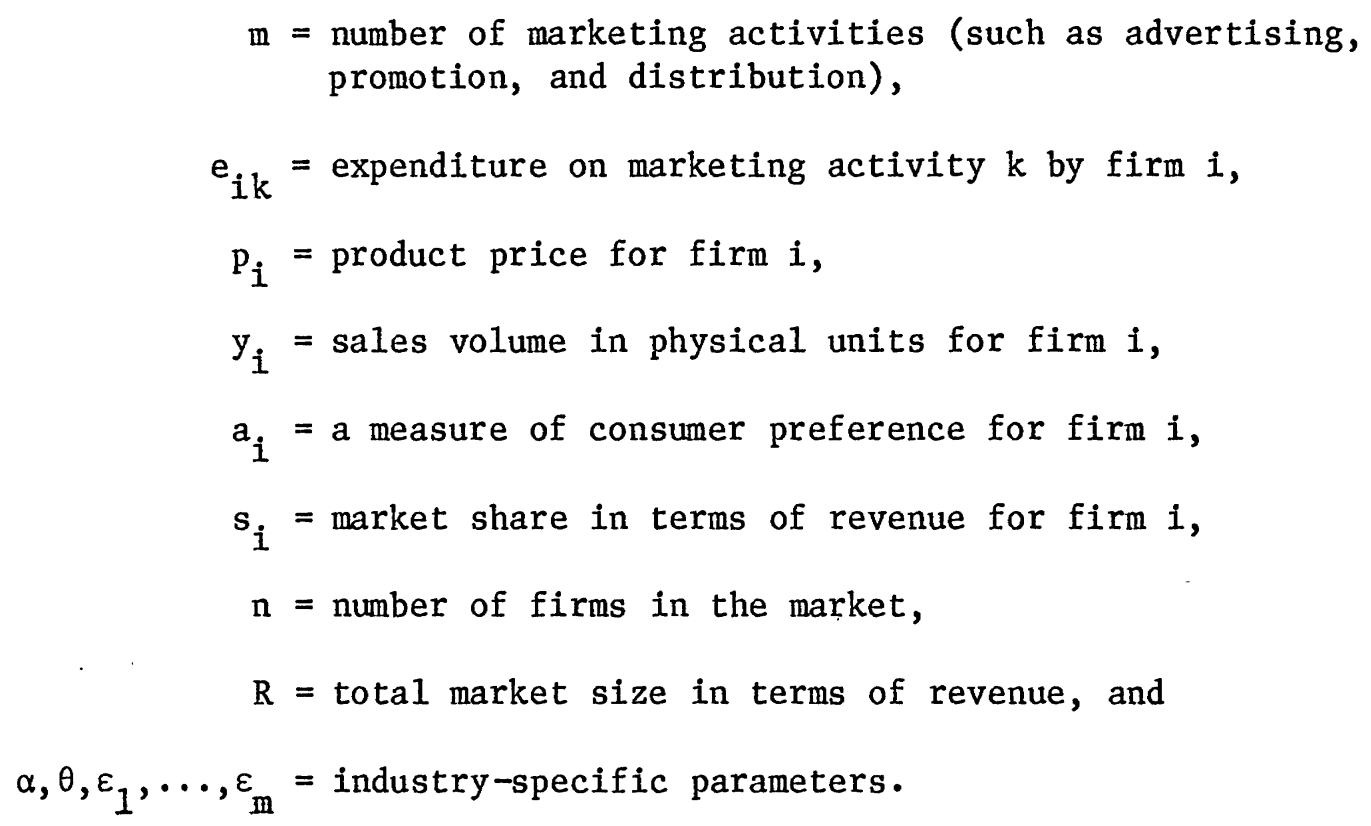

Following the previous research on market share attraction models, it is assumed that the market shares are given by

$$
s_{i}=\frac{a_{i} p_{i}^{-\alpha}\left(\prod_{k=1}^{m} e_{i k}^{\varepsilon_{k}}\right)}{\sum_{j=1}^{n} a_{j} p_{j}^{-\alpha}\left(\prod_{k=1}^{m} e_{j k}^{\varepsilon_{k}}\right)},
$$

which does not permit the marketing instrument response parameters, $\alpha$ and $\varepsilon_{k}, k=1,2, \ldots, m$, to vary across the firms in the industry. Kotler (1965) made the same assumption in a simulation study. Naert and Wenerbergh (1981) found that a model incorporating this restriction resulted in a better empirical fit with the data than the more general model which permitted the response parameter to vary across the firms.

Be11, Keeney, and Little (1975) suggest that one might construct a model of total market size as a function of the total attraction for all the firms 
in the market (that is, the denominator in equation (1)). Assuming decreasing marginal utility, it is reasonable to assume that the total market size is a nondecreasing, concave function of the total attraction. A specific functional form for the total market size is assumed here:

$$
R=\left[\sum_{j=1}^{n} a_{j} p_{j}^{-\alpha}\left(\prod_{k=1}^{m} e_{j k}^{\varepsilon_{k}}\right)\right], 0 \leq \theta<1,
$$

where $\theta$ is an industry-specific parameter. Kotler (1965) used the same functional form in his simulation study. To the best of my knowledge, the above model of market size has not been used in empirical research, probably because it is nonlinear. However, a model which has frequently been used to mode1 industry size is the log-linear model

$$
R=\bar{a} \mathrm{p}_{\mathrm{A}}^{-\bar{\alpha}}\left(\begin{array}{ll}
\prod_{k=1}^{\mathrm{m}} & \mathrm{e}_{\mathrm{Tk}}^{\mathrm{k}}
\end{array}\right),
$$

where $p_{A}$ is the average price in the industry and $e_{T k}$ is the total industry expenditure on marketing activity $\mathrm{k}$ (for example, Urban, 1969). It could be argued that mode1 (3) is an approximation of equation (2). The two models are identical if $\mathrm{n}=1$.

It is assumed that the production cost for a firm is given by $c_{i} y_{i}^{\beta}$, where $c_{i}$ is a firm-specific cost parameter and $\beta$ measures the scale effect in production. ${ }^{3}$ This functional form is consistent with the frequent use of loglinear specifications in empirical research on cost functions (for example, Intriligator, 1978, Chapter 8). It is obvious that the sales volume in physical units for a firm is given by

$$
y_{i}=\frac{s_{i} R}{p_{i}}
$$


It is assumed that each firm attempts to maximize its profit by controlling its decision variables: price, $p_{i}$; and expenditures on the various marketing activities, $e_{i k}, k=1,2, \ldots, m$. The optimization problem for a firm is given by

$$
\begin{aligned}
& \operatorname{Maximize} v_{i}=p_{i} y_{i}-c_{i} y_{i}^{\beta}-\sum_{k=1}^{m} e_{i k}, \\
& p_{i}, e_{i k} \geq 0, \quad k=1,2, \ldots, m,
\end{aligned}
$$

where $y_{i}$ is given by equations (1), (2), and (4).

\section{$\underline{\text { Parameter Restrictions }}$}

For the above model to be a reasonable representation of reality, it is necessary to restrict the range of possible values for the parameters. The cross-price elasticity of a firm's sales is given by

$$
\eta_{i j}=\frac{p_{j}}{\left(p_{i} y_{i}\right)} \cdot \frac{\partial\left(p_{i} y_{i}\right)}{\partial p_{j}},
$$

which, using equations (1), (2), and (4), can be shown to be

$$
\eta_{i j}=\alpha(1-\theta) s_{j}, \quad i \neq j .
$$

We clearly expect the cross-price elasticities to be nonnegative; that is, if a firm increases the price of its product, it is expected that the sales volumes of its competitors will increase or remain constant. Since the parameter $\alpha$ is of course positive, for $\eta_{i j}$ to be always nonnegative and positive in at least some case, it is necessary that $\theta<1$, which is consistent with the assumption in equation (2).

The sales elasticity of expenditure on marketing activity $k$ is given by

$$
\phi_{k}=\frac{e_{i k}}{\left(p_{i} y_{i}\right)} \cdot \frac{\partial\left(p_{i} y_{i}\right)}{\partial e_{i k}},
$$


which, using equations (1), (2), and (4), can be obtained to be

$$
\phi_{k}=\varepsilon_{k}\left[1-(1-\theta) s_{i}\right]
$$

It can be seen that the elasticity of marketing expenditures is a decreasing function of market share of the firm. If there are diminishing returns to scale in marketing for all firms, big or small, then $\varepsilon_{k}<1, k=1,2, \ldots, \mathrm{m}$. However, if there are increasing returns to scale initially (that is, for lowmarket-share firms) and diminishing returns later on (that is for high-marketshare firms), then it is possible that $\varepsilon_{k}>1$ for some, or all, marketing activities, and $\left(\theta \varepsilon_{k}\right) \leq 1$ for all marketing activities. Finally, if some marketing activity is characterized by increasing returns to scale regardless of the firm's size, then $\left(\theta \varepsilon_{k}\right)>1$ for that activity. Since the existence of economies of scale in marketing activities is controversial, we do not here directly restrict the range of possible values for the parameters $\varepsilon_{k}$. Finally, we restrict the parameter values such that the maximum profit a firm can earn is always finite. It is clearly reasonable to expect the parameter values to be such that no combination of the decision variables will permit a firm to earn infinitely high profits. Consider a monopolistic market, that is, $\mathrm{n}=1$. In that case, the optimization problem (5) can be rewritten as

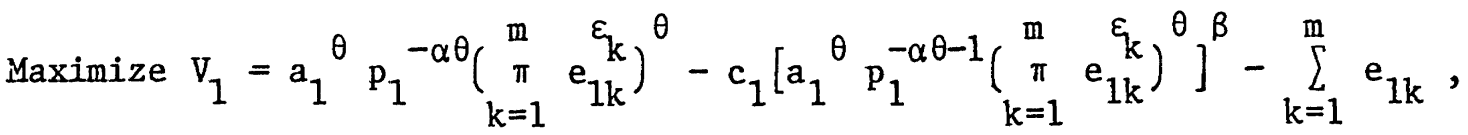

$$
\begin{aligned}
& \mathrm{p}_{1}, \mathrm{e}_{1 \mathrm{k}} \geq 0, \mathrm{k}=1,2, \ldots, \mathrm{m} .
\end{aligned}
$$

In Appendix A it is shown that for the optinal profit in problem (6) to be finite it is necessary that 


$$
1+\alpha \theta-\theta\left(\sum_{k=1}^{m} e_{k}\right)>0,
$$

and

$$
\beta>\frac{\alpha \theta}{1+\alpha \theta-\theta\left(\sum_{k=1}^{\mathrm{m}} \varepsilon_{\mathrm{k}}\right)} \text {. }
$$

Accordingly, it is assumed here that the above two conditions are satisfied.

\section{Nash Equilibrium}

The above model is analyzed with respect to equilibrium among the firms in the industry, assuming that entry prevention is not a prior constraint. Furthermore, it is assumed that the firms behave like "Cournot competitors," and hence Nash equilibrium is the appropriate solution concept. The Cournot assumption is that a firm solves its optimization problem by assuming that the values of the decision variables for its competitors are given. A Nash equilibrium is obtained when each firm in the market simultaneously solves problem (5) under this assumption.

Where there are economies of scale, as in the above model, there will be discontinuities in the reaction functions, and multiple Nash equilibria may exist (Dixit, 1979). In that case it is not possible to point to a deterministic outcome of competition in the oliogopoly.

Here we shall not attempt to derive completely the Nash solution(s). Instead, we derive a set of necessary conditions which partially characterize any Nash equilibrium to the above model, and deduce the practical implications of these conditions.

The solution to problem (5) may lie on the boundary, that is, $p_{i}=\infty$ and $e_{i k}=0, k=1,2, \ldots, m$, which would imply that $y_{i}=0$ and $s_{i}=0$; or it may be an interior solution. If problem (5) for a particular firm has an interior solution, that firm would have $y_{i}>0$ and $s_{i}>0$, that is, it would have a strictly positive sales volume. In this paper we will focus our 
attention on firms which have a strictly positive sales volume at the equilibrium solution.

The first-order optimality conditions for an interior solution to problem (5) are given by

$$
\frac{\partial v_{i}}{\partial p_{i}}=y_{i}+\frac{\partial y_{i}}{\partial p_{i}}\left(p_{i}-c_{i} \beta y_{i}^{\beta-1}\right)=0
$$

and

$$
\frac{\partial v_{i}}{\partial e_{i k}}=\frac{\partial y_{i}}{\partial e_{i k}}\left(p_{i}-c_{i} \beta y_{i}^{\beta-1}\right)-1=0 \text {, for } k=1,2, \ldots, m .
$$

Clearly a firm can earn zero profits by setting $p_{i}=\infty$ and $e_{i k}=0$, $\mathrm{k}=1,2, \ldots, \mathrm{m}$; therefore, producing a strictly positive volume can be the optimal solution for a firm only if

$$
v_{i}=p_{i} y_{i}-c_{i} y_{i}^{\beta}-\sum_{k=1}^{m} e_{i k} \geq 0
$$

At any Nash equilibrium, all firms producing a strictly positive volume (that is, $y_{i}>0$ ) must satisfy conditions (9) through (11). We now explore the practical implications of these conditions.

\section{Results}

It should be emphasized that the results presented here are valid for any Nash equilibrium to the above model. Therefore, the fact that multiple Nash equilibria may exist does not detract from the validity of these results. Furthermore, these results are valid for all firms which produce a strictly positive volume and hence have a strictly positive market share at equilibrium.

The mathematical derivation of the results is given in Appendix B. Here we present only the results. Define 


$$
\delta=\alpha\left(\frac{1}{\beta}-1\right)+\sum_{k=1}^{m} \varepsilon_{k} .
$$

In Appendix B it is shown that

$$
s_{i} \geq s_{\min }= \begin{cases}0, & \text { for } \delta \leq 1 \\ \frac{1-1 / \delta}{1-\theta}, & \text { for } \delta \geq 1 ;\end{cases}
$$

that is, at equilibrium each firm must have market share equal to zero or above a certain minimum value, $\mathrm{s}_{\mathrm{min}}$. It can be easily shown that conditions, (7) and (8) imply $(1 / \delta)>\theta$. Therefore, in equation (13), the minimum market share, $\mathrm{s}_{\mathrm{min}}$, is always less than 1 , as expected intuitively.

It is also shown that the ratio of profit to the sales revenue of a firm is related to the firm's market share:

$$
\frac{v_{i}}{p_{i} y_{i}}=\frac{1-\delta\left[1-(1-\theta) s_{i}\right]}{1+\alpha\left[1-(1-\theta) s_{i}\right]} \text {. }
$$

Finally, it is shown in Appendix $B$ that the ratio of expenditure on a marketing activity to the sales revenue of a firm is related to the firm's market share:

$$
\frac{\mathrm{e}_{i k}}{\mathrm{p}_{i} \mathrm{y}_{i}}=\frac{\varepsilon_{k}\left[1-(1-\theta) s_{i}\right]}{1+\alpha\left[1-(1-\theta) s_{i}\right]} .
$$

The next section discusses and interprets results (13) through (15), and relates them to previous empirical research.

\section{INTERPRETATION}

$\underline{\text { Minimum Market Share }}$

Economic theory has long argued that there exists a minimum optimal scale for a firm (for example, Scherer, 1980, Chapter 4). This conclusion is derived from assumptions about the cost structure of a firm which imply that a firm's long run unit cost function is either U-shaped or L-shaped. However, this does 
not take into account the nature of the demand in the industry under analysis. The strategic planning literature suggests that a small firm can be successful if it can carve out a "niche" for itself (for example, Hammermesh, Anderson, and Harris, 1978). Translated into economic language this means that minimum firm size decreases as scope for product differentiation increases. It is intuitively evident that the minimum firm size must be a function of both the cost structure of the firms in the market and the demand structure of the market.

Equation (13) states that at equilibrium in the industry, each active competitor must have market share above a certain minimum value, $s_{\min }$. This minimum firm size is a function of the cost structure of the firms (reflected here in $\beta$ ) and the demand structure of the market (reflected here in $\alpha$, $\theta$, and $\left.\varepsilon_{k}, k=1,2, \ldots, m\right)$. Incidentally, it is not surprising that the above model exhibits this threshold effect in market share, since Karnani (1982a) has shown that another oligopoly model which is equivalent to the model discussed here exhibits the same property. 4

From equations (12) and (13) it is easy to see that as the economies of scale in production increase (that is, as $\beta$ decreases), the minimum firm size increases, as expected. This is consistent with theories in economics on minimum firm size (Scherer, 1980, Chapter 4). It can also be seen that as $\varepsilon_{k}$ increase, the minimum firm size increases. That is, the greater the elasticities of marketing activities, the greater is the minimum firm size. Clearly, the greater the minimum firm size, the greater is the likelihood that that industry will be concentrated. Therefore, the above model predicts that industries in which marketing activities play a significant role are likely to be more concentrated than industries in which marketing activities are not important. This is consistent with the empirical literature on advertising 
(see, for example, Comanor and Wilson, 1974). Finally, it can be seen that as $\alpha$ decreases, minimum firm size decreases. It was pointed out earlier that cross-price elasticities are given by

$$
\eta_{i j}=\alpha(1-\theta) s_{j}, \quad i \neq j
$$

Therefore, the lower the value of $\alpha$, the lower are the cross-elasticities, and the lower is the substitutability among the products in the market; that is, the greater is the degree of segmentation in the market. The above result is consistent with the concept of segmentation in strategic market planning. The more difficult it is to segment the market, the more difficult it is for small competitors to be profitable. A more detailed discussion of the strategic implications of this threshold effect in market share can be found in Karnani (1982b).

\section{Profitability-Market Share Relationship}

The above model predicts that profitability and market share are related by equation (14). Differentiating equation (14) with respect to $s_{i}$ yields

$$
\frac{\partial}{\partial s_{i}}\left(\frac{v_{i}}{p_{i} y_{i}}\right)=\frac{(1-\theta)(\delta+\alpha)}{\left[1+\alpha\left[1-(1-\theta) s_{i}\right]\right]^{2}} \text {. }
$$

Recalling that $\theta<1$, it can easily be seen that the right-hand side of the above equation is positive. Thus profitability and market share are positively related. The shape of equation (14) is indicated in Figure 1.

Insert Figure 1 about here

There is, of course, abundant empirical evidence in the literature from the fields of marketing, business policy, and industrial organization that profitability and market share are positively correlated. Probably the bestknown example of such research is the PIMS project (for example, Abell and 
Hammond, 1979, Chapter 6). Relationship (14) predicted by the above model is obviously consistent with this evidence. 5 However, the empirical research on profitability has usually assumed that profitability is a linear function of market share. Equation (14) suggests that a nonlinear relationship is probably more appropriate.

Equation (16) measures the slope of the relationship between profitability and market share. Clearly the steeper this relationship, the more advantageous it is to have a high market share. We now investigate how this slope depends on the various parameters. From equations (12) and (16) it is easily shown that

$$
\frac{\partial}{\partial \beta} \cdot \frac{\partial}{\partial s_{i}}\left(\frac{v_{i}}{p_{i} y_{i}}\right)<0 .
$$

Therefore, the greater the economies of scale in production, the steeper is the relationship between profitability and market share. It is usually argued that one of the underlying causes of the positive relationship between profitability and market share is economies of scale. It is thus intuitively expected that the greater the production economies of scale, the steeper is the relationship, as stated by equation (17).

From equations (12) and (16) it can be seen that

$$
\frac{\partial}{\partial \varepsilon_{k}} \cdot \frac{\partial}{\partial s_{i}}\left(\frac{v_{i}}{p_{i} y_{i}}\right)>0, \quad k=1,2, \ldots, m .
$$

It may be recalled that the demand elasticity of expenditure on marketing activity $k$ is directly proportional to $\varepsilon_{k}$. Therefore, the model predicts that the greater are the demand elasticities of marketing expenditures, the steeper is the relationship between profitability and market share. From equation (15) it can be seen that the ratio of expenditure on marketing activity $k$ 
to sales revenue is directly proportional to $\varepsilon_{k}$. Therefore, the steepness of the profitability-market share relationship and the ratio of expenditure on marketing activity $k$ to sales revenue are both increasing functions of the parameter $\varepsilon_{k}$. On this basis it is hypothesized that the ratio of marketing expenditures to sales is positively related to the steepness of the profitability/market-share relationship. There is, in fact, empirical evidence to support this hypothesis. One of the results of the PIMS research project, reported by Abell and Hammond (1979), is a cross-tabulation of return on investment, relative market share, and the ratio of marketing expenditures to sales, which is reproduced here in Table 1. From Table 1 it is clear that high market share is more important for businesses with a high marketing/sales ratio than for businesses with a low marketing/sales ratio, which is consistent with the above hypothesis derived from the model presented here.

Insert Table 1 about here

Marketing/Sales Ratio

The above model predicts that the ratio of expenditure on a marketing activity to sales is a function of the firm's market share, as indicated in equation (15). Differentiating this equation with respect to $s_{i}$ we obtain

$$
\frac{\partial}{\partial s_{i}}\left(\frac{e_{i k}}{p_{i} y_{i}}\right)=\frac{-\varepsilon_{k}(1-\theta)}{\left[1+\alpha\left[1-(1-\theta) s_{i}\right]\right]^{2}}<0,
$$

where it may be recalled that $\theta<1$. Therefore, firms with larger market shares will have lower ratios of marketing expenditures to sales than firms with lower market shares. There is considerable empirical evidence to support this conclusion. Lilien (1978) found that firms with high market shares had 
both lower advertising to sales ratios and lower total marketing to sales ratios than firms with low market shares. Bailey (1975) also showed lower marketing to sales ratios for products in the "top $25 \%$ of their product class." In a cross-sectional study using the PIMS data base, Farris and Buzzel (1979) found a significant negative relationship between the ratio of advertising and promotion expenditures to sales and market share.

It is worth noting that the above model predicts this relationship without assuming economies of scale in marketing. In fact, the model predicts this relationship even if there are always diminishing returns to scale in marketing, that is, $\varepsilon_{k}<1, k=1,2, \ldots, m$. Farris and Buzzel (1979) hypothesize a negative relationship between marketing/sales ratio and market share, and give economies of scale in marketing as a reason for this hypothesis. However, current marketing thought suggests that marketing instruments exhibit diminishing returns to scale (Parsons and Schultz, 1976, p. 144). Farris and Buzzel (1979, p. 115) also recognize that the existence of economies of scale is "highly controversial" and suggest that "other explanations are possible for this pattern." The model presented here explains the observed relationship regardless of whether there are economies or diseconomies of scale in marketing. 


\section{APPENDIX A}

\section{PARAMETER RESTRICTION}

The optimization problem for a monopolist is given by equation (6). The first order optimality conditions for problem (6) are given by

$$
\frac{\partial \mathrm{V}_{1}}{\partial \mathrm{p}_{1}}=-\alpha \theta \frac{\mathrm{R}_{1}}{\mathrm{p}_{1}}+\beta(\alpha \theta+1) \frac{\mathrm{C}_{1}}{\mathrm{p}_{1}}=0,
$$

and

$$
\frac{\partial V_{1}}{\partial e_{1 j}}=\varepsilon_{j} \theta \frac{R_{1}}{e_{1 j}}-\varepsilon_{j} \theta \beta \frac{C_{1}}{e_{1 j}}-1=0 \text {, for } j=1,2, \ldots, m \text {, }
$$

where, to simplify the notation, we have defined

$$
\mathrm{R}_{1} \equiv \mathrm{a}_{1}{ }^{\theta} \mathrm{p}_{1}{ }^{-\alpha \theta}\left(\underset{\mathrm{k}=1}{\mathrm{~m}} \mathrm{e}_{1 \mathrm{k}}^{\varepsilon_{\mathrm{k}}}\right)^{\theta},
$$

and

$$
C_{1} \equiv c_{1} a_{1}^{\theta \beta} p_{1}^{-\beta(\alpha \theta+1)}\left(\underset{k=1}{m} e_{1 k}^{\varepsilon_{k}}\right)^{\beta \theta}
$$

After substituting the value of $C$ from equation (18) into equation (19) and rearranging, we have

$$
e_{1 j}=\frac{\varepsilon_{j}{ }^{\theta}}{\alpha \theta+1} \cdot R_{1}, \quad \text { for } j=1,2, \ldots, m \text {. }
$$

From equations (20) and (21), after some algebraic manipulation, we can obtain

$$
e_{1 j}=\varepsilon_{j} K_{1} p_{1} \exp \left(\frac{-\alpha \theta}{1-\theta \sum_{k=1}^{m} \varepsilon_{k}}\right) \text {, for } j=1,2, \ldots, m \text {, }
$$

where $\mathrm{K}$ is some constant depending on the various parameters. After substituting equation (22) into problem (6) and simplifying the expression, the 
optimization problem for a monopolist can be rewritten as

$$
\begin{aligned}
\underset{\mathrm{p}_{1} \geq 0}{\operatorname{Maximize}} \mathrm{V}_{1} & =\mathrm{K}^{\prime} \mathrm{p}_{1} \exp \left(\frac{-\alpha \theta}{1-\theta \sum_{\mathrm{k}=1}^{\mathrm{m}} \varepsilon_{\mathrm{k}}}\right) \\
& -\mathrm{K}^{\prime \prime} \mathrm{p}_{1} \exp \left(-\beta-\frac{\beta \alpha \theta}{1-\theta \sum_{\mathrm{k}=1}^{\mathrm{m}} \varepsilon_{\mathrm{k}}}\right),
\end{aligned}
$$

where $K^{\prime}$ and $K^{\prime \prime}$ are some constants depending on the various parameters.

We now impose the condition that the optimal value of $V_{1}$ in problem (23) be finite. First, consider the case where $\left(\theta \sum_{k=1}^{m} \varepsilon\right)<1$. To ensure that $v_{1}$ does not go to infinity for $p_{1}=0$, it is necessary that

$$
\frac{-\alpha \theta}{1-\theta \sum_{k=1}^{\mathrm{m}}}>-\beta-\frac{\beta \alpha \theta}{1-\theta \sum_{\mathrm{k}=1}^{\mathrm{m}} \varepsilon_{\mathrm{k}}},
$$

which can be rewritten as

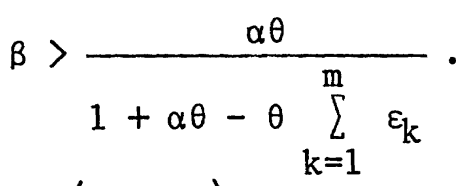

If $\left(\theta \sum_{k=1}^{m} \varepsilon_{k}\right)=1$, then to ensure that $v_{1}$ does not go to infinity for $p_{1}=0$, it is necessary that $\beta>1$.

Finally, consider the case where $\theta\left(\sum_{k=1}^{m}\right) \varepsilon_{k}>1$. To ensure that $v_{1}$ does not go to infinity as $p_{1}+\infty$, it is necessary that

$$
\frac{-\alpha \theta}{1-\theta \sum_{\mathrm{k}=1}^{\mathrm{m}} \varepsilon_{\mathrm{k}}}<-\beta-\frac{\beta \alpha \theta}{1-\theta \sum_{\mathrm{k}=1}^{\mathrm{m}} \varepsilon_{\mathrm{k}}}
$$

It is easy to show that for condition (24) to be satisfied, it is necessary that 


$$
1+\alpha \theta-\theta \sum_{k=1}^{m} \varepsilon_{k}>0,
$$

and

$$
\beta>\frac{\alpha \theta}{1+\alpha \theta-\theta \sum_{k=1}^{\mathrm{m}} \varepsilon_{k}} \text {. }
$$

From the above discussion it can be seen that to ensure that the optimal value of $V_{1}$ in problem (6) is finite, conditions (25) and (26) must both be satisified -- regardless of whether $\theta \sum_{k=1}^{m} \varepsilon_{k}$ is less than, equal to, or greater than 1 . 


\section{APPENDIX B}

\section{MATHEMATICAL DERIVATION OF RESULTS}

In this appendix we derive equations (13) through (15) from conditions (9) through (11). Substituting equations (1) and (2) into (4), differentiating (4) with respect to $p_{i}$, and after some algebraic simplification, we obtain

$$
\frac{\partial y_{i}}{\partial p_{i}}=-\frac{y_{i}}{p_{i}}\left[1+\alpha\left[1-(1-\theta) s_{i}\right]\right]
$$

Similarly, we can obtain

$$
\frac{\partial y_{i}}{\partial e_{i k}}=\frac{\varepsilon y_{i}}{e_{i k}}\left[1-(1-\theta) s_{i}\right], \quad k=1,2, \ldots, m .
$$

From equations (9) and (10) we can obtain

$$
y_{i}+\frac{\partial y_{i}}{\partial p_{i}} \cdot \frac{\partial e_{i k}}{\partial y_{i}}=0, \quad k=1,2, \ldots, m .
$$

Substituting equations (27) and (28) into the above equation and rearranging yields

$$
e_{i k}=p_{i} y_{i} \cdot \frac{\varepsilon_{k}\left[1-(1-\theta) s_{i}\right]}{1+\alpha\left[1-(1-\theta) s_{i}\right]}, \quad k=1,2, \ldots, m,
$$

which is the equation (15) reported in the paper.

Equation (10) can be rewritten as

$$
c_{i} y_{i}^{\beta}=\frac{1}{\beta}\left[p_{i} y_{i}-y_{i} \cdot \frac{\partial e_{i k}}{\partial y_{i}}\right]
$$

Substituting equations (28) and (29) into the above equation we have

$$
c_{i} y_{i}^{\beta}=\frac{p_{i} y_{i}}{\beta}\left[1-\frac{1}{1+\alpha\left[1-(1-\theta) s_{i}\right]}\right] \text {. }
$$


Substituting equations (29) and (30) into condition (11) and simplifying we have

$$
v_{i}=p_{i} y_{i} \cdot \frac{1-\delta\left[1-(1-\theta) s_{i}\right]}{1+\alpha\left[1-(1-\theta) s_{i}\right]} \geq 0,
$$

where $\delta$ is defined as

$$
\delta=\alpha\left(\frac{1}{\beta}-1\right)+\sum_{k=1}^{m} \varepsilon_{k} .
$$

Equation (31) directly yields the results given in (13) and (14). 
Figure 1. Profitability Market-Share Relationship

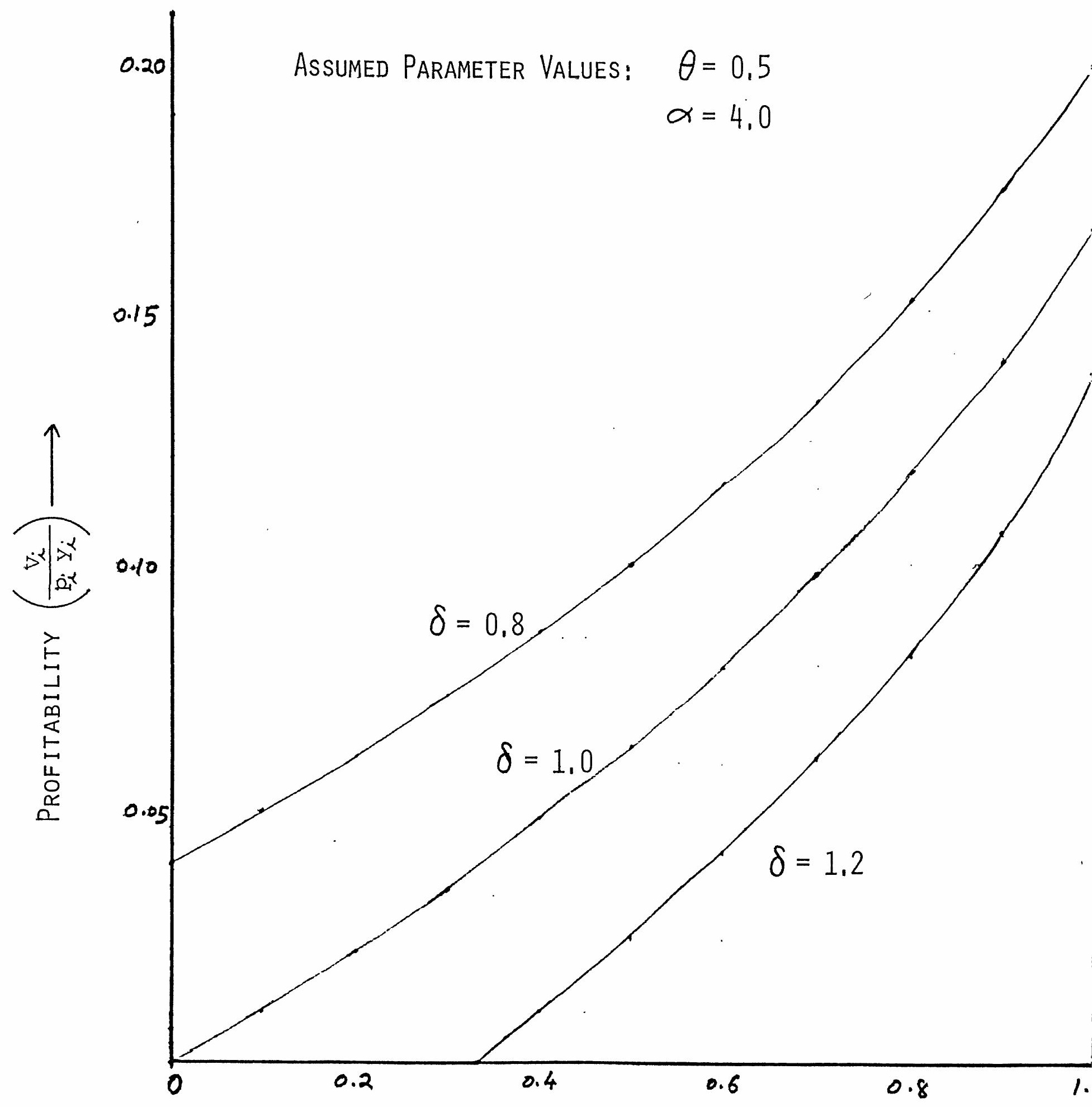

Market Share $\left(s_{i}\right) \longrightarrow$ 
TABLE 1

INTERACTION BETWEEN THE MARKETING/SALES RATIO AND THE PROFITABILITY-MARKET SHARE RELATIONSHIP

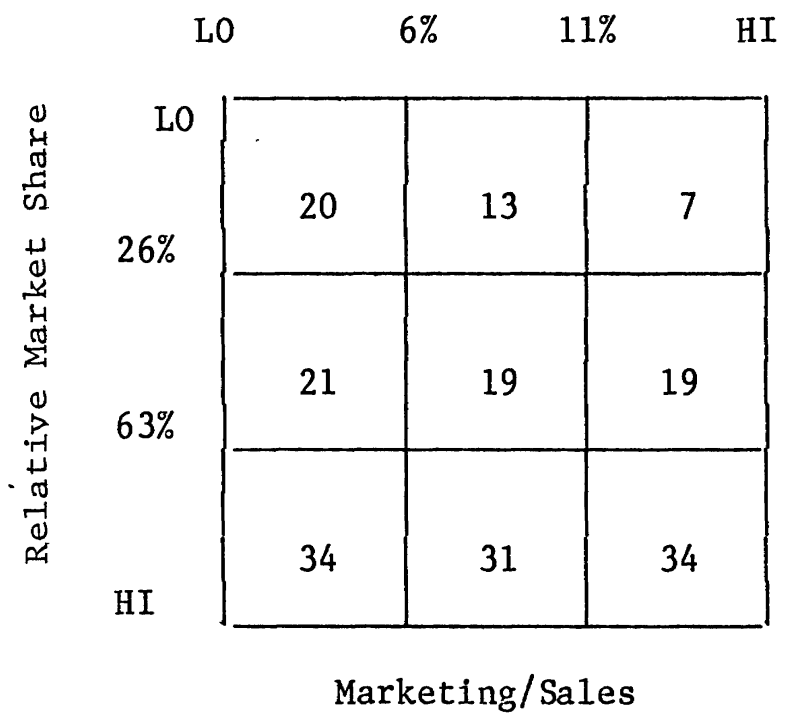

Note: The numbers in the boxes denote ROI.

Reproduced from Abel1 and Hammond (1979), p. 281. 
FOOTNOTES

1. See Bel1, Keeney, and Little (1975) for some examples of such studies.

2. See also Barnett (1976).

3. By contrast, the previous game-theoretic research in this area, which was cited earlier, has assumed that there are constant returns to scale (that is, $\beta=1$ ) in production.

4. The model discussed by Karnani (1982a) assumes that the decision variables for the firms are output in units $\left(y_{i}\right)$ and marketing expenditures ( ${ }_{i k}$, $k=1,2, \ldots, m)$. Because of the different ways $p_{i}$ and $y_{i}$ enter the optimization problem (5), the model in Karnani (1982a) is easier to solve than the one presented here.

5. Strictly speaking, the empirical studies have usually defined profitability as return on investment, whereas equation (14) defines profitability as return on sales. If the relationship between sales and investment is characterized by constant returns to scale, then the two measures of profitability are equivalent. If the relationship is characterized by increasing returns to scale, as is probably true in most industries, then the conclusion deduced from the above model would only be reinforced. 
Abe11, Derek F., and John S. Hammond. Strategic Market Planning. Englewood Cliffs, N.J.: Prentice-Ha11, 1979.

Bailey, Ear1 L. Marketing Cost Ratios of U.S. Manufacturers. New York: The Conference Board, 1975.

Balch, Michael. "Oligopolies, Advertising, and Non-cooperative Games." In H. W. Kuhn and G. P. Szego (eds.), Differential Games and Related Topics. New York: North-Ho1land, 1971.

Baligh, H. H., and L. E. Richartz. "Variable-Sum Game Models of Marketing Problens." Journal of Marketing Research 4 (May 1967): 173-185.

Be11, David E.; Ralph L. Keeney; and John D. C. Little. "A Market Share Theorem." Journal of Marketing Research 12 (May 1975): pp. 136-141.

Chatfield, Christopher. "A Comment on a Market Share Theorem." Journal of Marketing Research 13 (August 1976): 309-311.

Comanor, W., and T. Wilson. Advertising and Market Power. Cambridge, Mass.: Harvard University Press, 1974.

Dixit, Avinash. "A Model of Duopoly Suggesting a Theory of Entry Barriers." The Bel1 Journal of Economics 10, no. 1 (Spring 1979): 20-32.

Farris, Paul W., and Robert D. Buzze11. "Why Advertising and Promotional Costs Vary: Some Cross-Sectional Analyses." Journal of Marketing 43 (Fal1 1979): $112-122$.

Friedman, L. "Game Theory Models in the Allocation of Advertising Expenditure." Operations Research 6 (September-0ctober 1958): 699-708.

Hammermesh, R. G.; M. J. Anderson, Jr.; and J. E. Harris. "Strategies for Low Market Share Businesses." Harvard Business Review 56, no. 3 (May-June 1978): 95-102.

Karnani, Aneel. "Minimum Market Share." Working Paper, Graduate School of Business Administration, The University of Michigan, 1982(a).

- "An 01igopoly Mode1 Implying a Threshold Effect in Market Share." Proceedings of the Academy of Management Annual Meeting, New York, August 1982(b), pp. 36-40.

Kotler, Philip. "Competitive Strategies for New Product Marketing over the Life Cycle." Management Science 12, no. 4 (December 1965): 104-119.

Lilien, Gary L. Advisor 2: A Study of Industrial Marketing Budgeting." Cambridge, Mass.: The Advisor Project, 1978. 
Mills, H. D. "A Study in Promotional Competition." In F. M. Bass et al. (eds.), Mathematical Models and Methods in Marketing. Homewood, II1.: Richard D. Irwin, 1961.

Naert, Philippe A., and Alain Bultez. "Logically Consistent Market Share Models." Journal of Marketing Research 10 (August 1973): 334-340.

, and M. Weverbergh. "On the Prediction Power of Market Share Attraction Mode1s." Journal of Marketing Research 18 (May 1981): 146-153.

Nakanishi, Masao, and Lee G. Cooper. "Parameter Estimation for a Multiplicative Competitive Interaction Mode1--Least Squares Approach." Journal of Marketing Research 11 (August 1974): 303-311.

Parsons, Leonard J., and Randall L. Schultz. Marketing Models and Econometric Research. New York: North-Holland, 1976.

Scherer, F. M. Industrial Market Structure and Economic Performance, 2d edition. Chicago: Rand McNally, 1980.

Schmalensee, Richard. "A Model of Promotional Competition in 01igopoly." The Review of Economic Studies 43 (October 1976): 493-507.

Simon, Hermann. "An Analytical Investigation of Kotler's Competitive Simulation Mode1." Management Science 24 (October 1978): 1462-1473.

Skakun, Melvin F. "Advertising Expenditures in Coupled Markets--A GameTheoretic Approach." Management Science 11 (February 1965): B42-47.

- "A Dynamic Model of Competitive Marketing in Coupled Markets." Management Science, 12 (August 1966): B525-530. 